\title{
Study on the Relationship Between Term Structure of Treasury Interest Rate and Stock Market Valuation
}

\author{
Yanliang Zhang ${ }^{1, \mathrm{a},{ }^{*}}$ and Yue Zhao ${ }^{1, \mathrm{~b}}$
}

\author{
${ }^{I}$ School of Finance, Shandong University of Finance and Economics, Jinan, P.R. China \\ azhyanliang@sina.com, ${ }^{b}$ zhaoy9999@126.com \\ *Corresponding author
}

\begin{abstract}
In recent years, with the rapid development of China's macro economy, the scale of the financial market is also constantly expanding, so the status of the stock market and bond market in the macro economy is also constantly improving, especially the relationship between China's national debt market and the stock market is also increasingly close. Therefore, it is necessary to study the linkage between the Treasury bond market and the stock market. In January 2008 to December 2017 as samples, this article selects the Treasury yields at sight and weighted average p/e ratio of stock market monthly data as sample, using the Nelson-Siegel can be derived from the model of slope, curvature and level three characteristic factor, and further combined with the weighted average p/e ratio of the stock market to build VAR model, and analyzes their relationship. The conclusion shows that there is a significant negative correlation between the level factor and the stock market valuation level, while there is no significant correlation between the slope and curvature factor and the stock market valuation level. Therefore, to improve the issuance structure of Treasury bonds, optimize the number of Treasury bonds of different maturities and improve the pricing efficiency of Treasury bonds can reduce the systemic risk of the Treasury bond market to a certain extent. This is of great significance to the development of China's national debt market.
\end{abstract}

Keywords: term structure of Treasury bond interest rate, stock market valuation, nelson-siegel model

\section{INTRODUCTION}

As China's economy turns to high-quality development in recent years, the GDP growth rate is lower than that of previous years and remains within a reasonable and stable range. However, a large amount of money issued to stimulate the economy after the financial crisis cannot be naturally digested by the economic system in a short time, which leads to the excess capacity in China's enterprise sector and the accumulation of risks in the financial sector. Therefore, the Chinese government proposes to carry out "three cuts, one reduction and one supplement" and supply-side reform in the enterprise sector to adjust production activities and realize the transformation of economic growth from old drivers to new ones. In addition, the government has proposed that the financial sector resolutely fight against and defuse major risks to ensure a smooth transition of China's economy in the process of shifting gears.

From the perspective of the international situation, along with the gradual interest rate rise of the federal reserve under the low dollar index and the slow rise of international oil price, the external appreciation of assets falls in price and the expectation of imported inflation makes the systemic risk of China's financial market passively rise. Combined with the rising of domestic financial assets, the risk of infectious increases between the different market, it is necessary to deeply analyze the relationship between stock market and bond market in China, looking for specific conduction path on the mutual influence between two markets, to make the macroeconomic regulation and control policy and systemic financial risk prevention and control to provide the right ideas.
The linkage between various financial markets is gradually enhanced, so the risks of a single market are easy to spread to other markets. This paper will start with the characteristic value of the term structure of Treasury interest rate to elaborate the interaction between the bond market and the valuation level of the stock market, so as to provide effective suggestions for the regulators to prevent and control systemic financial risks. For institutional investors, cross-market asset allocation is a necessary condition for building a long-term, stable and profitable portfolio. This paper will systematically elaborate the mechanism of linkage between China's stock market and bond market, which can provide a reference for institutional investors to formulate timing strategies when conducting portfolio management.

\section{REVIEW OF LITERATURE}

Foreign studies on the relationship between the term structure of Treasury bond interest rate and the stock market started earlier. For example, Resnick and Shoesmith (2002) believed that the long-short spread could effectively predict the decline of the stock market one month in advance, and in their out of sample simulation from 1970 to 1999, they confirmed that the return obtained by investing with the long-short spread forecast would be $2.29 \%$ higher than that of the buy-and-hold strategy on average every year[1]. Empirical analysis of UK data shows a two-way predictability between equity premium and government bond yields, Such as Clare (1994)[2]. Fraser (1995) found that the yield of British government bonds could predict the equity premium[3], while Lekkos and Milas (2004) confirmed that the UK's equity premium could also predict the yield to maturity of government bonds[4]. Subsequently, some scholars propose that the relationship between the stock 
market and the term structure of Treasury bond interest rate is non-linear. For example, Kanas (2009), using more than a century of data from the UK, finds that there is a non-linear relationship between stock risk premium and Treasury bond term premium, which is a stochastic regime switching process[5]. Then Kanas(2010) made a further analysis from the two dimensions of asymmetry and regional system transfer caused by positive and negative slope factors of term structure of interest rates. The results show that only when the slope factor is positive and the volatility of equity premium is low can the slope factor be predictive of equity premium[6]. There are few researches on the relationship between the term structure of Treasury bond interest rate and the stock market in China. Xing hairong (2010) discussed the relationship between the interest rate of long-term and short-term Treasury bonds and equity premium, and believed that the interest rate of 1-year Treasury bonds and 10-year Treasury bonds had a good explanation of equity premium, while the relationship between slope factor and equity premium was not significant, which was different from the conclusions of relevant foreign studies[7]. Xia qing, Pan $\min (2011)$ believe that there is a substitution relationship between China's stock assets and national debt assets, and the conversion of the stock market has a significant impact on the term structure of national debt interest rate[8]. Tang rui(2012) discussed the impact of stock market volatility on term structure of interest rate from the perspective of long-term and short-term, and believed that stock market volatility could be used as a forecasting tool for term structure of interest rate[9]. Ba shusong(2017) studied the relationship between the level of inflation, the market value of the stock market and the term structure of Treasury interest rate, and believed that there was a long-term cointegration relationship between the level of inflation, the market value of the stock market and the term structure of Treasury interest rate, while the level of inflation and the market value of the stock market were difficult to cause significant changes in the level factor[10].

In addition, most domestic literatures discuss the linkage between the bond market and the stock market from the perspective of asset prices. For example, Fang guohao (2017) found that there was a weak positive spillover effect between the stock market and the bond market in the short term[11]. However, He yiqing (2012) believes that in most time periods, the stock market transmits the reverse volatility spillover effect to the national debt market through the corporate bond market in the short term[12]. Other scholars believe that there is asymmetry in the interaction between the two markets. For example, Luo ronghua (2017) believes that there is a nonlinear linkage between China's stock market and bond market, and the interpretation strength of the non-linear model is better than that of the linear model[13]. Zheng guozhong (2014) et al. divided the market conditions from 2005 to 2014 into three stages: bull market, bear market and shock market for back-test, and found that the linkage between the two markets was significantly stronger in the bull market stage than in the bear market stage and shock market stage[14]. Hou xianping (2016) found that before the 2008 financial crisis, only the stock market had a financial contagion effect on the national debt market, while after the financial crisis, the bond market also had a risk transmission effect on the stock market[15].

\section{THE EMPIRICAL STUDY ON TERM STRUCTURE OF TREASURY INTEREST RATE AND STOCK MARKET VALUATION}

\subsection{Nelson-Siegel Model}

Nelson-siegel model (NS model) is a parameter estimation model proposed by Nelson C. and Siegel A. (1987) to fit the term structure of bond interest rate. The principle is to first establish the function of the forward instantaneous interest rate against the remaining term, and then deduce the functional form of the spot interest rate through this function. The instantaneous forward interest rate function assumed by the NS model is shown in formula (1).

$$
f(0, t)=\beta_{0}+\beta_{1} \exp \left(-\frac{t}{\tau_{1}}\right)+\beta_{2}\left(\frac{t}{\tau_{1}}\right) \exp \left(-\frac{t}{\tau_{1}}\right)
$$

According to formula 4.1, the functional form of spot rate can be deduced, as shown in formula (2).

$$
R(0, t)=\frac{\int_{0}^{t} f(s) d s}{t}=\beta_{0}+\beta_{1}\left[\frac{1-\exp \left(-\frac{t}{\tau_{1}}\right)}{\frac{t}{\tau_{1}}}\right]+\beta_{2}\left[\frac{1-\exp \left(-\frac{t}{\tau_{1}}\right)}{\frac{t}{\tau_{1}}}-\exp \left(-\frac{t}{\tau_{1}}\right)\right]
$$

From the equation, $t$ is the maturity of the bond, $r$ is the yield to maturity of the bond of different maturities, $\beta_{0}, \beta_{1}, \beta_{2}$ are estimated parameters, $\tau_{1}$ is index depletion rate. We use these two formulas to reasonably estimate and fit the term structure of bond interest rate.

\subsection{Data Selection and Processing}

In order to analyze the dynamic change of the term structure of China's Treasury bond interest rate in the medium and long term, this paper selected the quotation of the inter-bank bond market from January 2008 to the end of each month in
December 2017, conducted programming with $\mathrm{R}$ language and fitted the term structure of China's Treasury bond interest rate with the help of NS model. The data came from the official website of China bond registration and settlement corporation.

This paper uses R-project to write parameters, search algorithm, and estimate the parameters of NS model. In order to ensure the estimation accuracy of each parameter, 10000 times of data fitting were performed for each phase in this paper. We selected the optimal solution from all the fitting results as the parameter fitting value in this period. 


\subsection{Model Building}

For further analysis of our country national debt term structure of interest rates and changes in the relationship between stock market valuations, we select the NS model to estimate the term structure of interest rates of national debt levels (LE), slope (SL), the curvature (CU) three characteristic values, in combination with the weighted average $\mathrm{p} / \mathrm{e}$ ratio $(\mathrm{PE})$ of the stock market to build VAR model.

The level value (LE), slope (SL) and curvature (CU) of the term structure of the interest rate of China's national debt are obtained from section 3.1. The data of Treasury bond yield came from the data of Treasury bond yield in the inter-bank bond market published on the official website of China bond registration and settlement corporation from January 2008 to the end of December 2017. The market average $\mathrm{P} / \mathrm{E}$ ratio $(\mathrm{PE})$ is the weighted average $\mathrm{P} / \mathrm{E}$ ratio at the end of the month after excluding the loss-making enterprises from January 2008 to December 2017. P/E data from the Resset database. The definition and source of variables are shown in table 1.

Table 1 Variable definitions and data sources

\begin{tabular}{c|c|c}
\hline $\begin{array}{c}\text { The variable } \\
\text { name }\end{array}$ & Variable meaning & The data source \\
\hline $\begin{array}{c}\text { The level of } \\
\text { value(LEt) }\end{array}$ & The yield to maturity of bonds over 30 years & by solving NS model \\
\hline $\begin{array}{c}\text { The slope(SLt) } \\
\text { The } \\
\text { curvature(CUt) }\end{array}$ & $\begin{array}{c}\text { The difference between long - and short-term } \\
\text { Treasury yields }\end{array}$ & by solving NS model \\
\hline $\begin{array}{c}\text { Market average } \\
\text { p/e(PEt) }\end{array}$ & The steepness of the Treasury rate curve & by solving NS model \\
\hline
\end{tabular}

\subsection{Stationarity Test}

When constructing the VAR model, stationarity test of each

variable is required. Since unstable variables will experience pseudo-regression during Granger causality test, ADF method is adopted in this paper to test the stationarity of each variable, and Eviews6.0 software is used to process the data. The stationarity test results are shown in table 2.

Table 2 Stationarity test

\begin{tabular}{c|c|c|c|c|c|c}
\hline \multirow{2}{*}{$\begin{array}{c}\text { The } \\
\text { variable } \\
\text { name }\end{array}$} & \multirow{2}{*}{$\begin{array}{c}\text { ADF test } \\
\text { value }\end{array}$} & \multicolumn{2}{|c|}{ Critical value of significance level } & \multirow{2}{*}{ P values } & \multirow{2}{*}{ smoothness } \\
\cline { 3 - 6 } & -3.788260 & -2.579818 & -2.885863 & -3.486064 & 0.0040 & smooth \\
\hline LE & -2.817783 & -3.486064 & -2.885863 & -2.579818 & 0.0588 & smooth \\
\hline SL & -8.491578 & -3.486064 & -2.885863 & -2.579818 & 0.0000 & smooth \\
\hline CU & -2.727858 & -3.486064 & -2.885863 & -2.579818 & 0.0723 & smooth \\
\hline PE & -2.783 &
\end{tabular}

As can be seen from the ADF test results, The $\mathrm{P}$ value of the variable LE is 0.0040 , indicating that it is stable at the significance level of $1 \%$. The P value of variable SL is 0.0588 , indicating that it is stable at the significance level of $10 \%$. The $P$ value of variable CU is 0.0000 , indicating that it is stable at the significance level of $1 \%$. The $\mathrm{P}$ value of variable $\mathrm{PE}$ is 0.0723 , indicating that it is stable at the significance level of $10 \%$. Therefore, the unconstrained VAR model can be directly constructed for subsequent analysis without differential treatment.

\subsection{Granger Causality Test}

Granger causality test is to test whether the data of two groups of time series are statistically sequential. If two groups of time series data can pass the Granger causality test, it is considered that there is a statistical causal relationship between the two groups of data, but it is not considered that they have a logical causal relationship. In this paper, Granger causality test is firstly used to test the causal relationship between level value (LE), slope (SL), curvature (CU) and $\mathrm{P} / \mathrm{E}(\mathrm{PE})$. Before Granger causality test, the optimal lag order of the VAR model should be determined. The test results of lag order are shown in table 3 . 
Table 3 Lag order

\begin{tabular}{c|c|c|c|c|c|c}
\hline Lag & LogL & LR & FPE & AIC & SC & HQ \\
\hline 0 & -771.6166 & NA & 8.478022 & 13.48898 & 13.58446 & 13.52774 \\
\hline 1 & -538.6912 & 445.5963 & $0.194968^{*}$ & $9.716369^{*}$ & $10.19375^{*}$ & $9.910135^{*}$ \\
\hline 2 & -523.4334 & $28.12756^{*}$ & 0.197711 & 9.729276 & 10.58856 & 10.07805 \\
\hline 3 & -513.4811 & 17.65447 & 0.22021 & 9.834454 & 11.07564 & 10.33825 \\
\hline 4 & -501.6481 & 20.1676 & 0.237912 & 9.906923 & 11.53001 & 10.56573 \\
\hline 5 & -492.9394 & 14.23676 & 0.272203 & 10.03373 & 12.03872 & 10.84755 \\
\hline
\end{tabular}

According to the information in table 3 , under the LR criterion, the optimal lag order is considered to be the second lag. Under the FPE criterion, it is considered that the optimal lag order is 1. Under the criterion, it is considered that the optimal lag order is 1 . Under the SC criterion, $t$ it is considered that the optimal lag order is 1 . Under HQ criterion, it is considered that the optimal lag order is 1. According to the comprehensive judgment of the information provided by the above criteria, we believe that the optimal lag order of the model is lag order 1 . Based on this, the Granger causality test with lag order of 1 was further conducted, and the results were shown in table 4.

Table 4 Granger causality test

\begin{tabular}{|c|c|c|c|c|}
\hline Number & The null hypothesis & F statistic & $\mathrm{P}$ values & conclusion \\
\hline 1 & SL is not LE's granger cause & 1.12379 & 0.2913 & can't reject the null hypothesis \\
\hline 2 & $\mathrm{LE}$ is not SL's granger cause & 2.6963 & 0.1033 & can't reject the null hypothesis \\
\hline 3 & CU is not LE's granger cause & 0.68913 & 0.4082 & can't reject the null hypothesis \\
\hline 4 & LE is not CU's granger cause & 0.16094 & 0.6890 & can't reject the null hypothesis \\
\hline 5 & SL is not CU's granger cause & 0.35085 & 0.5548 & can't reject the null hypothesis \\
\hline 6 & CU is not SL's granger cause & 5.45679 & 0.0212 & Reject null hypothesis \\
\hline 7 & $\mathrm{PE}$ is not LE's granger cause & 8.44504 & 0.0044 & Reject null hypothesis \\
\hline 8 & $\mathrm{LE}$ is not PE's granger cause & 5.48502 & 0.0209 & Reject null hypothesis \\
\hline 9 & $\mathrm{PE}$ is not SL's granger cause & 0.27329 & 0.6021 & can't reject the null hypothesis \\
\hline 10 & SL is not PE's granger cause & 0.01577 & 0.9003 & can't reject the null hypothesis \\
\hline 11 & $\mathrm{PE}$ is not CU's granger cause & 1.61285 & 0.2066 & can't reject the null hypothesis \\
\hline 12 & CU is not PE's granger cause & 0.68561 & 0.4094 & can't reject the null hypothesis \\
\hline
\end{tabular}

As can be seen from the granger causality test, first, the null hypothesis that PE is not granger cause of LE can be rejected at the significance level of $1 \%$, indicating that variable $\mathrm{PE}$ is granger cause of variable LE. The null hypothesis that LE is not granger reason for $\mathrm{PE}$ can be rejected at the significance level of $5 \%$, indicating that the variable LE is granger reason for PE, that is, the valuation level of the stock market and the horizontal value factor of the term structure of Treasury interest rate are granger reason for each other. This test result is consistent with the conclusion of theoretical analysis. Second, granger causality between variables of $\mathrm{PE}$ and $\mathrm{CU}$ inspection results are not through the test of significance, so we can't think the statistical causality exists between them, namely the valuation of the stock market and the curvature of the national debt term structure of interest rates there is no granger causality relation between characteristic factor, the part of conclusion is consistent with theoretical analysis. Finally, the granger causality test results show that the test results between variable PE and variable SL cannot pass the significance test, that is, we cannot assume that there is a statistical causal relationship between the valuation level of the stock market and the slope factor of the term structure of Treasury interest rate. This is inconsistent with the conclusion of theoretical analysis. The reason may be that the market segregation between China's national debt market and the stock market is relatively serious. Institutional investors can achieve cross-market asset allocation, while most individual investors can only invest in a single market. Therefore, in the empirical test based on monthly data, granger causality between slope factor and stock market valuation level cannot be obtained.

\subsection{Impulse Response Analysis}

On the basis of granger causality test, this paper further uses impulse response analysis to test the specific functional relationship between term structure of Treasury interest rate 
and stock market valuation level. After Eviews6.0 software calculation, the impulse response analysis group is shown in

figure 1.

Response to Cholesky One S.D. Innovations \pm 2 S.E.

Response of SL to SL

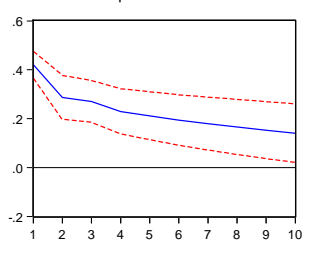

Response of PE to SL

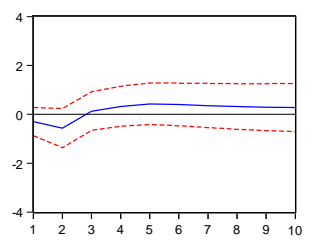

Response of LE to SL

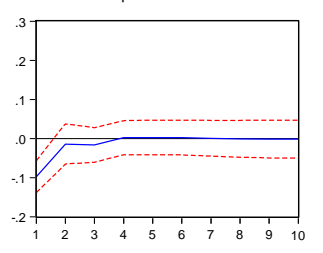

Response of $\mathrm{CU}$ to $\mathrm{SL}$

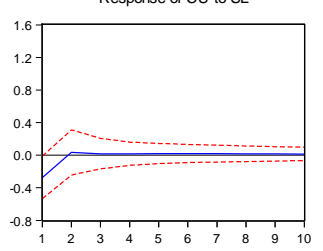

Response of SL to PE

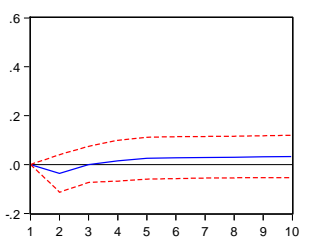

Response of PE to PE

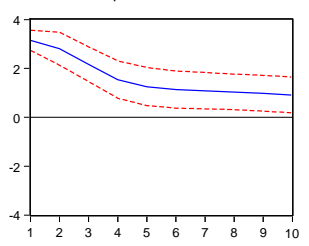

Response of LE to PE

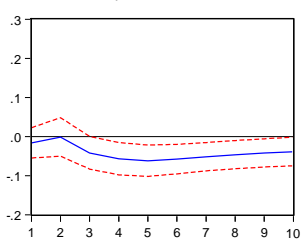

Response of $\mathrm{CU}$ to PE

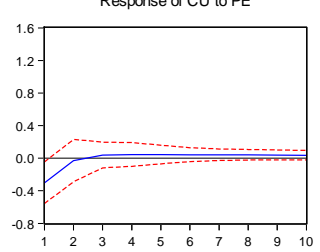

Response of SL to LE

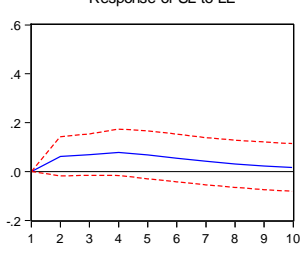

Response of PE to LE

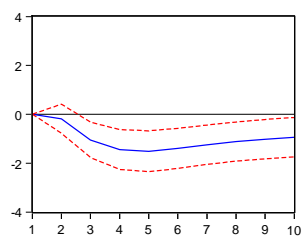

Response of LE to LE

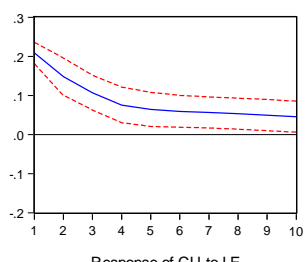

Response of CU to LE

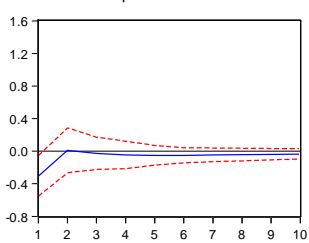

Response of SL to CU

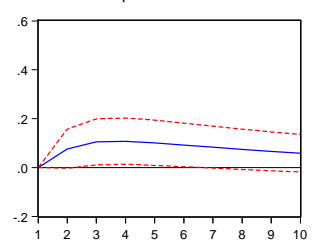

Response of $\mathrm{PE}$ to $\mathrm{CU}$

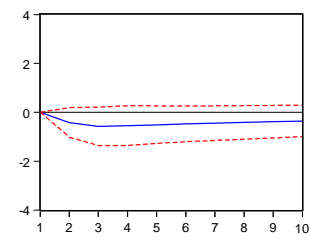

Response of LE to $\mathrm{CU}$

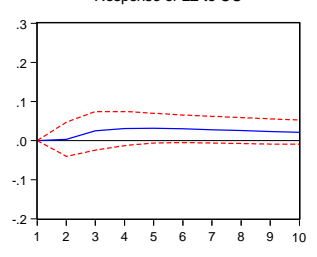

Response of $\mathrm{CU}$ to $\mathrm{CU}$

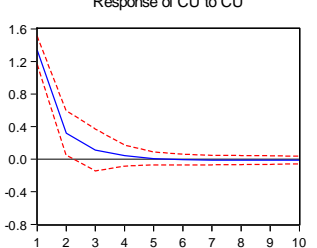

Figure 1 Impulse response analysis

As can be seen from the impulse response analysis in figure 1, In the national debt term structure of interest rates impact on stock market valuations, when given the level of the term structure of Treasury bond market value $\mathrm{L}$ a standard deviation of the positive impact, the valuation of the stock market in the first two PE period will not be significantly affected, and in the third period began to reverse significantly affected, and this effect decreases gradually, This result is consistent with the theoretical analysis. When a positive impact of a standard deviation is given to the variable SL, the variable $P E$ will not be affected by the change of variable $S$ in the first phase, but will be affected in the second phase in the opposite direction, and this effect gradually decreases. That is, with the increase of variable SL, variable PE will keep decreasing. However, because the zero axis is within the confidence interval, variable SL has no significant influence on variable PE. This result is different from the conclusion of theoretical analysis. When a positive shock of a standard deviation is given to the variable $\mathrm{CU}$, the variable $\mathrm{PE}$ is affected in a negative way from the first phase and decreases gradually. That is, with the increase of variable SL, variable $\mathrm{PE}$ will keep decreasing. However, since the zero axis is within the confidence interval, the effect of variable $\mathrm{CU}$ on variable PE is also not significant. This result is consistent with the theoretical analysis. Valuations in the stock market's influence on the national debt term structure of interest rates, when given variable $\mathrm{PE}$ a standard deviation of the positive impact, variable LE in the previous two period won't be affected by variables PE change, and in the third period began to reverse significantly affected, and this effect decreases gradually, namely as the variable rise of PE, variable LE will continue to decline, this result is consistent with the theoretical analysis part; When the positive impact of a standard deviation of variable PE is given, the variable SL will be significantly negatively affected in the first phase. However, from the second phase, the impact gradually decreases, and the positive impact will be changed in the fifth phase. That is, with the increase of variable PE, the variable SL will first decrease and then increase. However, after the second phase, because the zero axis is within the confidence interval, the impulse response result is not significant. This conclusion is consistent with the theoretical analysis. When the positive impact of a standard deviation of variable $\mathrm{PE}$ is given, the influence of variable CU is very small, and the zero axis is within the confidence interval, so the influence is not significant. It can be considered that the change of variable PE will not cause the change of variable CU. This result is consistent with the theoretical analysis.

To sum up, the results of impulse response analysis show that there is a significant inverse correlation between the level value factor of term structure of national debt interest rate and the level of stock market valuation. There is a negative relationship between the slope factor and the stock market valuation level, but it is not significant. There is no significant relationship between curvature factor and stock market valuation level. 


\subsection{Variance Decomposition}

On the basis of the VAR model, this paper further analyzes the variance decomposition of variables $\mathrm{LE}, \mathrm{SL}, \mathrm{CU}$ and $\mathrm{PE}$ to

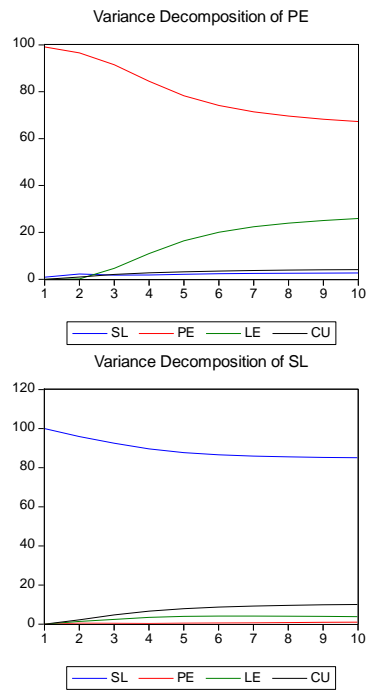

investigate the degree of interaction between these four variables in the long term. The variance decomposition results are shown in figure 2 .

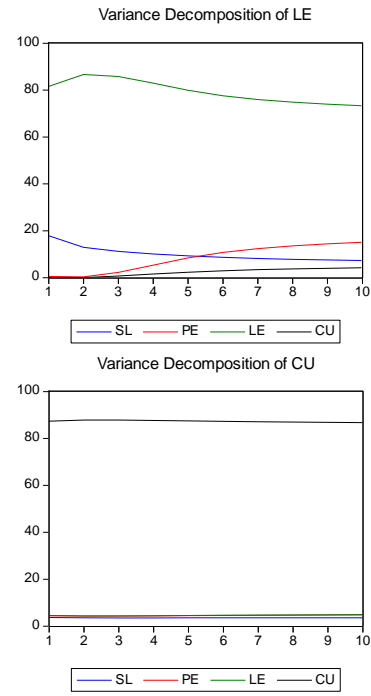

Figure 2 Variance decomposition

According to the results of variance decomposition, in terms of the impact of the term structure of Treasury interest rate on the valuation level of the stock market, in the long run, about $70 \%$ of the variation of variable PE is caused by its own change. The remaining $30 \%$ variation is caused by variables LE, SL and CU, among which the influence degree of variable $\mathrm{LE}$ on variable PE accounts for the majority. This result is consistent with the theoretical analysis. In the influence of stock market valuation level on term structure of Treasury interest rate, for the variable LE, in the short term, about $80 \%$ of its fluctuation is caused by the change of LE variable itself, and $20 \%$ is caused by the variable SL. In the long run, $80 \%$ of the fluctuation is also caused by the change of LE itself, but the remaining $20 \%$ fluctuation is caused by the change of variable $\mathrm{PE}$, which is consistent with the theoretical analysis. In the long run, about $85 \%$ of the fluctuation of variable SL is caused by the change of variable SL itself, and the remaining $15 \%$ is caused by variables LE, CU and PE. For the variable $\mathrm{CU}$, in the long run, about $90 \%$ of its total fluctuation is caused by the change of the variable $\mathrm{CU}$ itself, and the remaining $10 \%$ fluctuation is caused by the variables LE, SL and PE, but the influence degree is relatively small. It can be considered that the fluctuation of the variable $\mathrm{CU}$ is not affected by other factors, which is consistent with the theoretical analysis.

\section{CONCLUSIONS}

The three characteristic factors of level value, slope and curvature extracted by nelson-siegel model, Combined with the weighted average $\mathrm{p} / \mathrm{e}$ level of China's stock market, a VAR model was built to empirically study the relationship between the term structure of Treasury bond interest rate and the valuation level of the stock market. Combined with granger causality test, impulse response analysis and variance decomposition results, it can be proved that the horizontal value factor of the term structure of Treasury interest rate has a significant inverse effect on the valuation level of the stock market. Within the sample interval, the stock market valuation level also has a negative impact on the level value factor, and there is no significant linkage between the curvature factor and the stock market valuation level, which is consistent with the conclusion of the theoretical analysis. However, it fails to prove that there is a significant correlation between the slope factor and the stock market valuation level, which is inconsistent with the theoretical analysis results. This paper believes that the main reason lies in the serious market isolation between China's financial markets, so the linkage between slope factor and stock valuation level is difficult to be reflected in monthly data.

\section{REFERENCES}

[1] Resnick, B.G., "Market Timing of International Stock Markets using the Yield Spread", EFMA 2002 London meeting, 2002.

[2] Clare, A. D. and Thomas, S. H.,"Macroeconomic Factors, the APT and the UK Stock Market",Journal of Business Finance and Accounting. 1994,vo1.21, 309-330.

[3] Angela J. Black,Patricia Fraser, "U.K. STOCK RETURNS: PREDICTABILITY AND BUSINESS CONDITIONS".The Manchester school of economic and social studies. 1995 (Vo63) :85-102.

[4] Ilias Lekkos, Costas Milas, "Common Risk Factors in the U.S. and UK rate swap Markets: Evidence from a Nonlinear Vector Autoregression Approach", The Journal of Futures Markets. 2004(Vo124):221-250.

[5] Angelos Kanas, "The relation between the equity risk premium and the bond maturity premium in the UK: 19002006", Journal of Economics and Finance, Springer. 2009(vol. 33):111-127.

[6] Angelos Kanas, "A note on the relation between the equity risk premium and the term structure", Journal of Economics and Finance, Springer. 2010(vol.20):95-118. 
[7] Xing Hairong, “Analysis on the relationship between term structure of interest rate and equity premium", Dongbei University of Finance and Economics. 2010.

[8] Xia Qing,Pan Min,Wang Ting, "Cycle conversion of stock market and term structure of Treasury interest rate -- an analysis based on MS-VAR", journal of south china university of technology. 2011,13(06):35-41.

[9] Tang Rui,Chen Yu,Che Jiayin,Li Yang, "Analysis on the impact of stock market volatility on term structure of interest rate", China chief accountant. 2012(05):65-67.

[10] Ba Shusong,Yuan Jia,Liao Hui, "Inflation level, stock market value and term structure of Chinese Treasury bond interest rate", Financial development research. 2017(01):3-10. [11] Fang Guohao, "Research on spillover effects between China's stock market and bond market",Anhui university. 2017.

[12] He Yiqing,Chen Ping,"Empirical analysis of volatility spillover effects and dynamic correlation between stock and bond markets". 2012,34(01):87-92.

[13] Luo Ronghua, "Nonlinear characteristic analysis of bond linkage in China", Business accounting. 2017(05):46-48. [14] Zheng Guozhong,Zheng Zhenlong,"Dissimilation analysis of dynamic correlation and risk contagion among China's financial markets", Southeast Academic Research. 2014(02):79-88+247.

[15] Hong Xianping, "Research on financial contagion effect between Chinese stock market and bond market", Southwest jiaotong university. 2016. 